https://helda.helsinki.fi

\title{
The effect of anion complexation on the aromatic properties of aromatic and antiaromatic porphyrinoids
}

\section{Valiev, Rashid R.}

2020-12-21

Valiev , R R , Valiulina , L I , Fliegl , H \& Sundholm , D 2020 , ' The effect of anion complexation on the aromatic properties of aromatic and antiaromatic porphyrinoids ', New Journal of Chemistry, vol. 44 , no. 47 , pp. 20643-20650 . https://doi.org/10.1039/d0nj04470a

http://hdl.handle.net/10138/336148

https://doi.org/10.1039/d0nj04470a

acceptedVersion

Downloaded from Helda, University of Helsinki institutional repository.

This is an electronic reprint of the original article.

This reprint may differ from the original in pagination and typographic detail.

Please cite the original version. 


\title{
The effect of anion complexation on the aromatic properties of aromatic
}

\section{and antiaromatic porphyrinoids}

\author{
Rashid. R. Valiev ${ }^{\mathrm{a}, \mathrm{b},{ }^{*}}$, Lenara I. Valiulina ${ }^{\mathrm{c}}$, Heike Fliegl ${ }^{\mathrm{d}}$ and Dage Sundholm ${ }^{\mathrm{a}}$ \\ a) Department of Chemistry, Faculty of Science, University of Helsinki, P.O. Box 55 (A.I. Virtanens \\ plats 1), Helsinki FIN-00014, Finland \\ b) Tomsk Polytechnic University, 30 Lenin Avenue, 634050, Tomsk, Russia \\ c) Tomsk State University, 36 Lenin Avenue, 634050, Tomsk, Russia

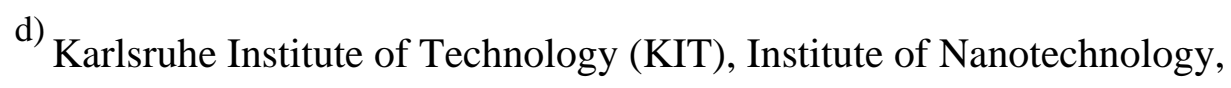 \\ Hermann-von-Helmholtz-Platz 1, 76344 Eggenstein-Leopold shafen, Germany \\ * Corresponding author: Rashid R. Valiev, phone: +79609754277, E-mail: rashid.valiev@helsinki.fi
}

\begin{abstract}
The effect of anion complexation on magnetically induced current densities and excitation energies of antiaromatic molecular rings has been investigated by calculations on expanded antiaromatic porphyrinoids such as orangarin, rosarin, amethyrin and on a theoretically predicted strongly antiaromatic hydrocarbon ring. Magnetically induced current densities and the lowest vertical excitation energies have been calculated at the density functional theory (DFT) and time-dependent DFT (TDDFT) levels using the M06-2X functional. Similar calculations have been performed on sapphyrin, cyclo[6]carbon and rubyrin, which are aromatic expanded porphyrinoids. The calculations show that anion complexation weakens the strength of the ring currents and the degree of (anti)aromaticity of the studied porphyrinoids and the antiaromatic hydrocarbon ring, because electronic charge is transferred from the anion to the molecular ring. The anion complexation weakens the calculated ring-current strength susceptibility of the antiaromatic porphyrinoids by 5-7 nA/T (25$30 \%$ ), by 6-16 nA/T (21-48\%) for the aromatic porphyrinoids, and by $8 \mathrm{nA} / \mathrm{T}$ (27\%) for the
\end{abstract}


antiaromatic hydrocarbon ring, whereas the current-density pathways remain for most molecules the same. Calculations on the lowest excited states show that the electronic transitions transfer electronic charge from the anion to the molecular ring. An antiaromatic heterocyclic molecular ring with five inner NH moieties that was constructed from the antiaromatic hydrocarbon ring was found to have a large $\mathrm{Cl}^{-}$complexation energy of $67.6 \mathrm{kcal} / \mathrm{mol}$.

Keywords: aromatic/antiaromatic nature, diatropic and paratropic ring currents, porphyrinoids, binding energy, complexation.

\section{Graphical Abstract}
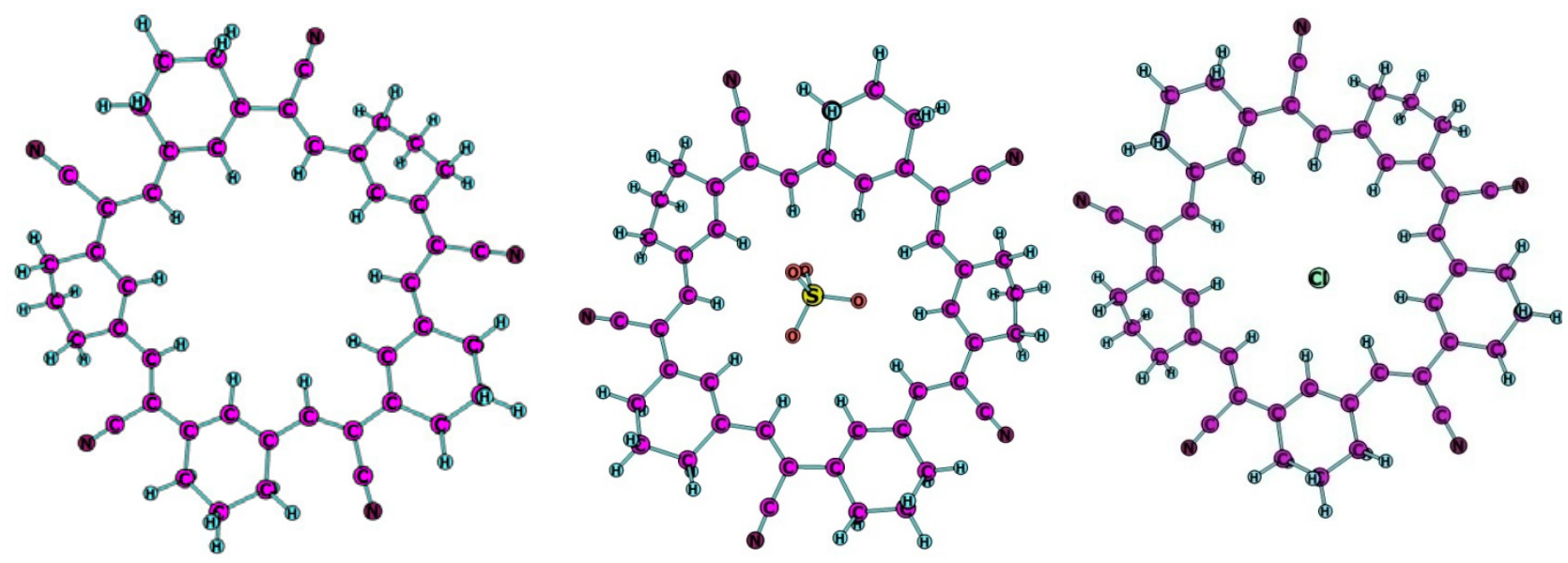

$I_{\text {tot }}=-28.4 n A / T$

$$
I_{\text {tot }}=-21.3 n A / T
$$

$$
\mathrm{I}_{\text {tot }}=-20.7 \mathrm{nA} / \mathrm{T}
$$

\section{Degree of antiaromaticity}




\section{INTRODUCTION}

Aromaticity is an important concept of cyclic organic molecules with conjugated bonds. ${ }^{1} \mathrm{It}$ encompasses a number of properties associated with chemical stability of ring-shaped molecules. ${ }^{2}$ Molecular aromaticity is not determined by a single criterion; instead, several criteria are commonly adopted for assessing the degree of aromaticity. Typically used ones are energetic, magnetic, ringcurrent, chemical, and structural criteria. The magnetic criterion and the ring-current criterion, that is, the strength of magnetically induced ring currents, are probably the most reliable means to obtain information about the degree of aromaticity of large ring-shaped molecules and of heterocyclic compounds consisting of several annelated rings. ${ }^{3-4}$ The ring-current criterion makes it possible to assess the aromaticity of such compounds not only qualitatively, but also quantitatively. Ring-current strengths and the norm of the anisotropy of the asymmetric magnetically induced current density tensor have been found to correlate well with aromatic stabilization energies. ${ }^{5,6}$ Ring-current strengths can even be used for determining the degree of aromaticity of the individual molecular rings in polycyclic molecules..$^{7-12}$ Experimental determination of the degree of aromaticity of polycyclic molecules with annelated heterocyclic rings is on the other hand complicated. ${ }^{2,13-15}$

The GIMIC method is a successful approach for assessing aromaticity according to the ringcurrent criterion. ${ }^{16}$ GIMIC calculations yield magnetically induced current densities that can be analyzed and visualized. The circulation direction of the current-densityflux with respect to the direction of the applied magnetic field as well as the strength of the ring current provide information about the aromatic character and degree of (anti)aromaticity. Diatropic ring currents, that is, the ring current in the classical direction with respect to the direction of the applied magnetic field show that the molecular ring or the entire molecule is aromatic, whereas antiaromatic molecules sustain ring currents in the opposite (paratropic) direction. Aromaticity is a good indicator for many properties of ring-shaped molecules. We have previously studied aromatic properties of porphyrinoids by calculating magnetically induced current densities. ${ }^{17-21}$ Porhpyrinoids can be applied as catalysts, drugs, organic semiconductors, liquid crystals, and nonlinear optical materials illustrating their 
relevance for chemistry, biology, medicine, optics and materials science. ${ }^{22-29}$ Previous theoretical studies showed that magnetically induced current densities are not only a fingerprint for aromaticity and aromatic pathways, but they can also be used for calculating magnetic susceptibilities and adopted as a noninvasive tool for estimating hydrogen bond energies. ${ }^{30,20}$ In addition, molecules with low-lying magnetic dipole-allowed electronic transitions can be identified through current density calculations.. ${ }^{31-32}$ The magnetically induced current density and spectroscopic properties of typical antiaromatic porphyrinoids such as orangarin, rosarin and amethyrin have recently been investigated. ${ }^{33}$ The calculations showed that molecules sustaining strongly paratropic ring currents have low-lying electronic states with large magnetic transition dipole moments and may even be closed-shell paramagnetic molecules. ${ }^{21} \mathrm{~A}$ recent study on amethyrin like expanded porphyrins showed that protonation of the nonaromatic species leads in some cases to a conversion to the antiaromatic form, which can be explained by the increase of paratropic currents. ${ }^{34}$

To the best of our knowledge, magnetically induced current densities of anionic porphyrinoid complexes have not been reported in the literature, yet. . Thus, it is not known how complexation with anions like $\mathrm{Cl}^{-}$or $\mathrm{SO}_{4}{ }^{2-}$ affects their magnetic properties and the degree of aromaticity. Anion complexation increases the number of valence electrons, which may lead to changes in the degree of antiaromaticity as the excess electron of the anion may to some extent transfer to electron deficient antiaromatic rings. Thus, a larger complexation energy can be obtained, because a partial electron transfer to the ring may decrease the antiaromatic character of the molecular ring.

In the present work, we are addressing this issue by investigating aromatic and antiaromatic porphyrinoids and novel molecular rings. Beside investigating the possible change in their currentdensity pathways and aromatic character, we also study how the complexation of the anion affects the electronic excitation spectra. Antiaromatic compounds are characterized by low-lying magnetic dipole transitions that are related to magnetically induced paratropic ring currents. Thus, changes in the aromatic character could also be observed as significant changes in the UV spectrum. The binding 
energies of the anion in the aromatic and antiaromatic porphyrinoid complexes have also been calculated.

\section{COMPUTATIONAL METHODS AND STUDIED MOLECULES}

The molecular structure of the ground state of sapphyrin(I), cyclo[6]carbon (II), rubyrin (III), orangarin (IV), rosarin (V) and amethyrin (VI) were optimized at the density functional theory (DFT) level using the M06-2X hybrid functional. ${ }^{35}$ The def2-TZVP basis sets were employed in all calculations. ${ }^{36}$ Calculations of the vibrational frequencies showed that the obtained molecular structures are minima on the potential energy surface. We constructed a strongly antiaromatic molecule (VII) by saturating the $\mathrm{CH}$ moieties of the outer perimeter of the benzene rings of the globally nonaromatic pentacyanobenzo[25]annulene. ${ }^{37}$ Since molecule VII has an odd number of electrons, we studied the closed-shell cation. Closed-shell molecules were constructed from VII by replacing the inner $\mathrm{CH}$ moieties of the six-membered rings with isoelectronic nitrogens. The number of electrons in the conjugated ring was adjusted by adding one (VIII), three (IX),five (X)inner hydrogens, respectively. The molecular structures of molecule VII, VIII, IX, X and their anion complexes with $\mathrm{Cl}^{-}$and the $\mathrm{SO}_{4}{ }^{2-}$ complex of VII were optimized at the same level of theory as used for the porphyrinoids. The molecular structures of the studied molecules are shown in Figures 1-3. The Cartesian coordinates are given as Electronic Supplementary Information (ESI). The calculated binding energies of the Cl'and $\mathrm{SO}_{4}{ }^{2-}$ complexes were corrected for basis-set superposition errors (BSSE) using the counterpoise (CP) correction calculated at the M06-2X level. ${ }^{38,39}$ The calculations were performed with GAUSSIAN $16 .{ }^{40}$

Nuclear magnetic shielding tensors and magnetically induced current densities were calculated at the M06-2X/def2-TZVP level. The magnetically induced current-density susceptibilities (in nA/T) were obtained by employing the GIMIC method, ${ }^{16,41}$ which has been interfaced to Gaussian. ${ }^{42}$ GIMIC uses the atomic orbital density matrix from the electronic structure calculation, the first-order magnetically perturbed density matrices from nuclear magnetic shielding calculations and basis-set 
information as input data. Integrated current strength susceptibilities were obtained by placing integration planes across relevant bonds. The strength of the current density along different pathways was obtained by numerical integration of the current density passing through the planes.

A population analysis based on occupation numbers (paboon) was used for estimating the effective charge of the $\mathrm{Cl}^{-}$anion in the complexes. The calculations were carried out at the B3LYP/def2-TZVP level of theory with Turbomole. ${ }^{43-46}$ Vertical excitation energies were calculated with Gaussian 16 at the time-dependent density functional theory (TDDFT) ${ }^{47}$ level using the M06-2X functional and the def2-TZVP basis sets. ${ }^{40,35}$

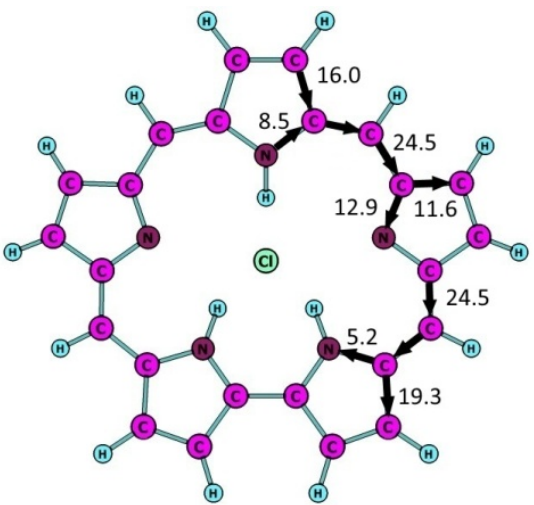

$\mathrm{I}\left[\mathrm{Cl}^{-}\right]$

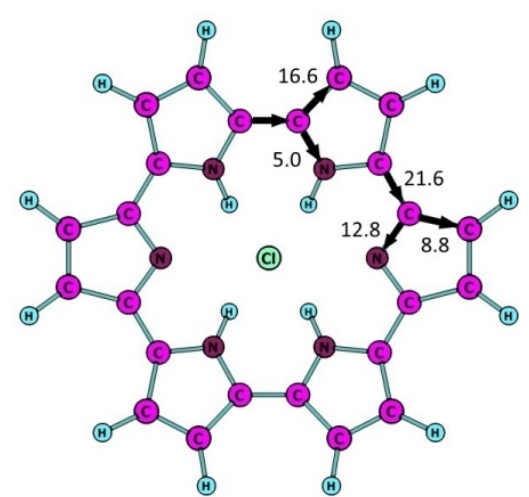

$\mathrm{II}\left[\mathrm{Cl}^{-}\right]$

$(44.3 \mathrm{kcal} / \mathrm{mol})$

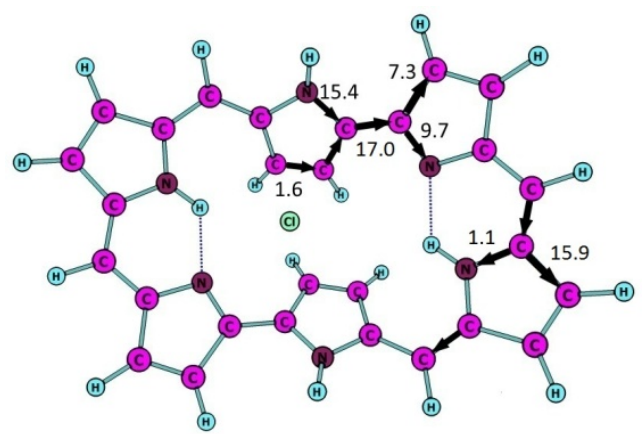

$\mathrm{III}\left[\mathrm{Cl}^{-}\right]$

$(14.5 \mathrm{kcal} / \mathrm{mol})$

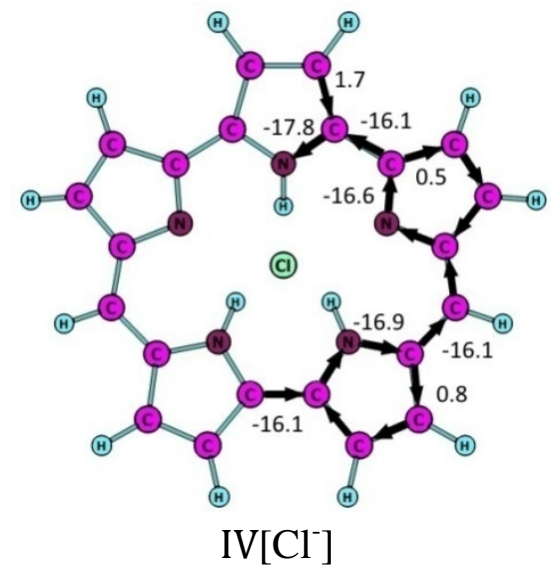

(33.2kcal $/ \mathrm{mol})$

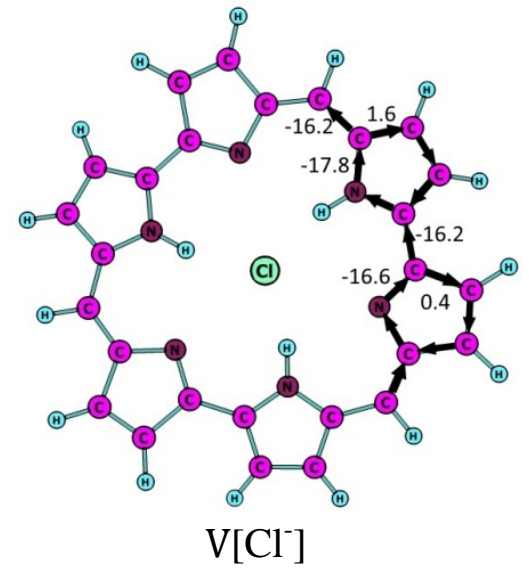

(27.1kcal/mol)

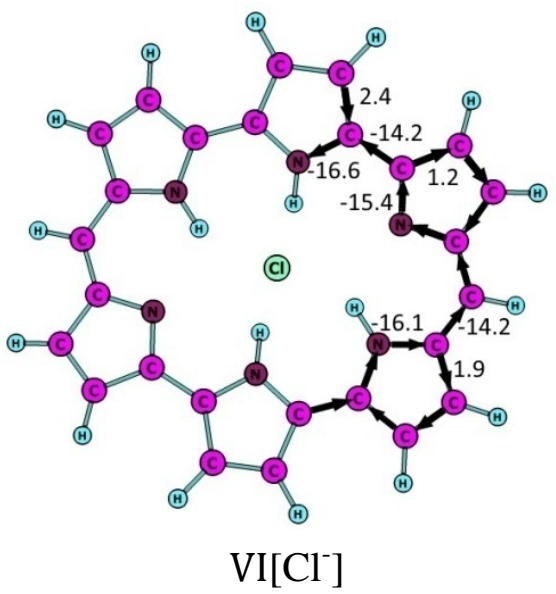

$(46.2 \mathrm{kcal} / \mathrm{mol})$ 
Figure 1. The molecular structures of the studied porphyrinoids. Magnetically induced ring-current strengths (in $\mathrm{nA} / \mathrm{T}$ ) and ring-current pathways calculated at the M06-2X/def2-TZVP level are also given. The ring-current pathways are shown with black arrows. BSSE-corrected binding energies (in $\mathrm{kcal} / \mathrm{mol}$ ) of the $\mathrm{Cl}^{-}$complexes calculated at the same level of theory are also reported.

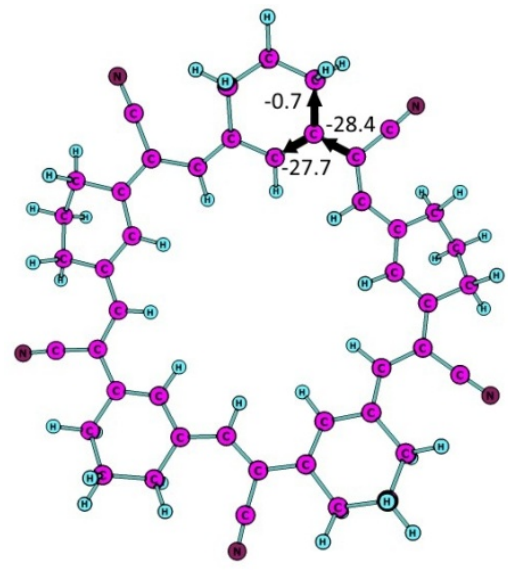

VII

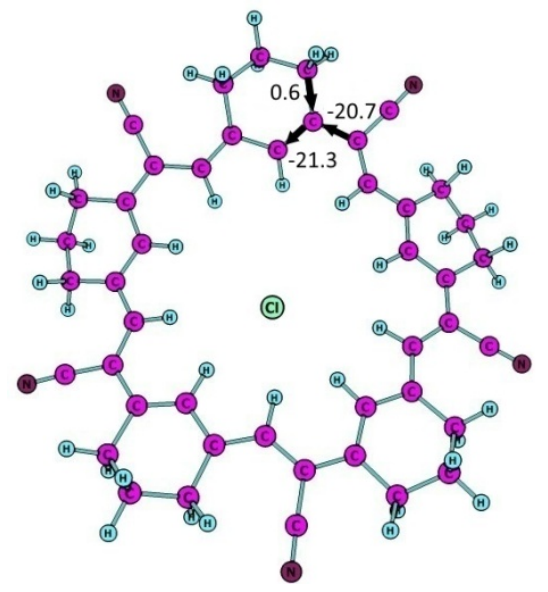

$\mathrm{VII}\left[\mathrm{Cl}^{-}\right]$

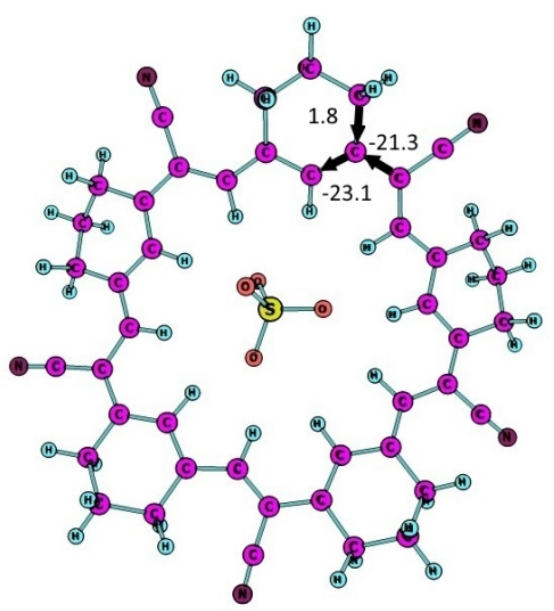

$\mathrm{VII}\left[\mathrm{SO}_{4}{ }^{2-}\right]$

Figure 2.The molecular structures of the antiaromatic molecule (VII) and its $\mathrm{Cl}^{-}\left(\mathrm{VII}^{2} \mathrm{Cl}^{-}\right]$) and $\mathrm{SO}_{4}{ }^{2-}$ (VII[SO$\left.{ }^{2-}\right]$ ) complexes. Magnetically induced ring-current strengths (in $\mathrm{nA} / \mathrm{T}$ ) and ring-current pathways calculated at the M06-2X/def2-TZVP level are also given.The ring-current pathways are shown with black arrows.

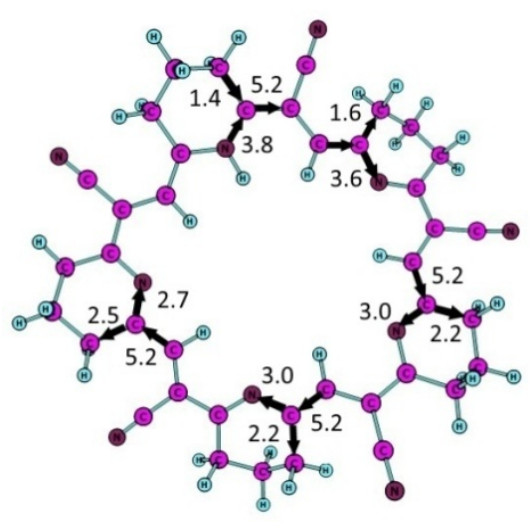

VIII

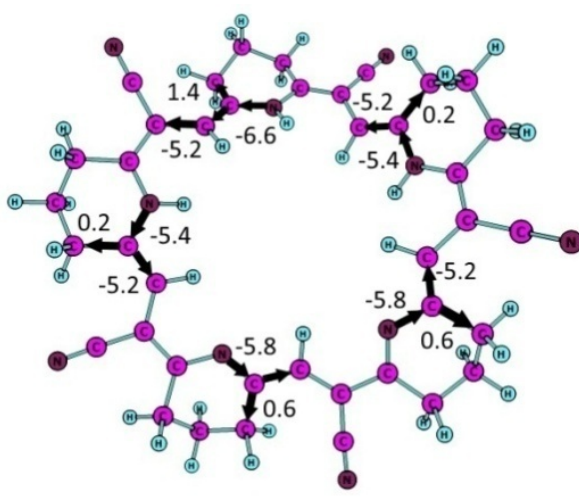

IX

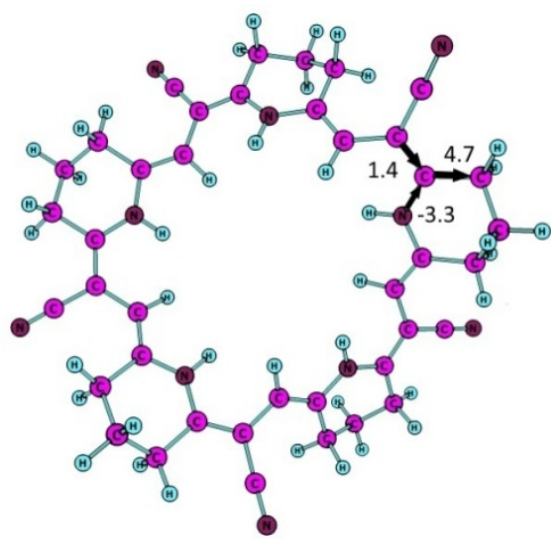

$\mathrm{X}$ 


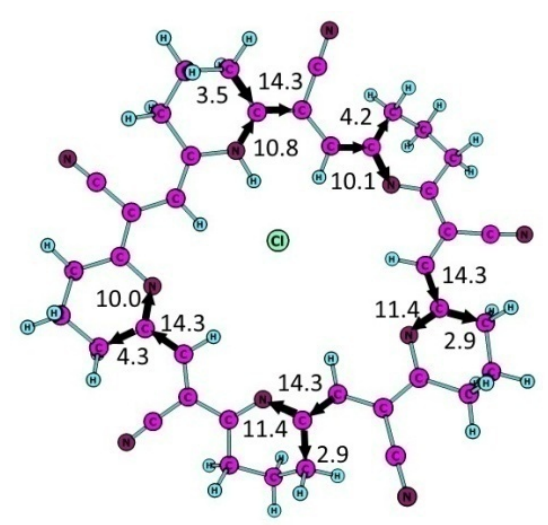

$\mathrm{VIII}\left[\mathrm{Cl}^{-}\right]$

$(41.1 \mathrm{kcal} / \mathrm{mol})$

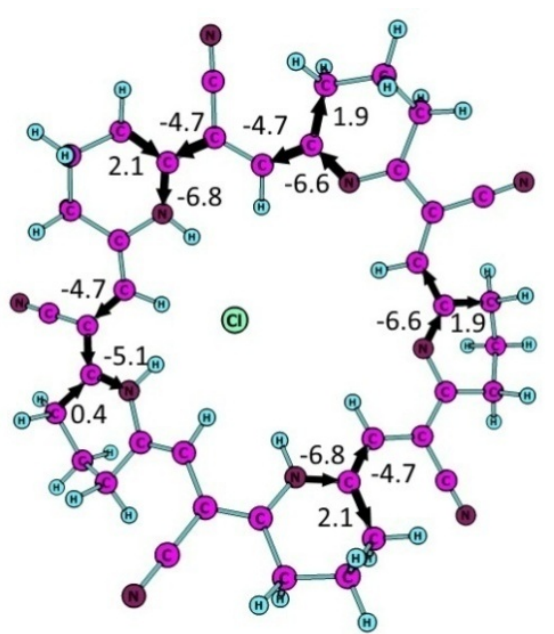

$\mathrm{IX}\left[\mathrm{Cl}^{-}\right]$

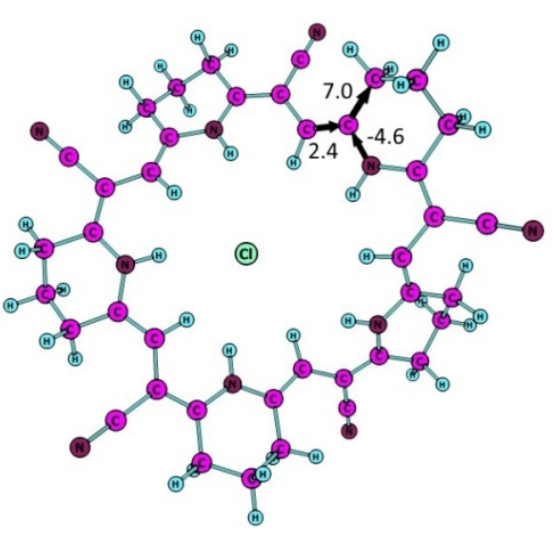

$\mathrm{X}\left[\mathrm{Cl}^{-}\right]$

$(54.4 \mathrm{kcal} / \mathrm{mol})$

$(67.6 \mathrm{kcal} / \mathrm{mol})$

Figure 3. The molecular structures of the studied heterocycles (VIII), (IX) and (X) and their $\mathrm{Cl}^{-}$ complexes. Magnetically induced ring-current strengths (in nA/T) and ring-current pathways calculated at the M06-2X/def2-TZVP level are also given. The ring-current pathways are shown with black arrows.BSSE-corrected binding energies (in $\mathrm{kcal} / \mathrm{mol}$ ) of the $\mathrm{Cl}^{-}$complexes calculated at the same level of theory are also reported.

\section{RESULTS AND DISCUSSION}

\subsection{Magnetically induced current densities}

\subsubsection{Aromatic porphyrinoids}

The integrated current strengths of the magnetically induced current density passing selected bonds of the studied porphyrinoids are given in Figure 1. The aromatic ring current pathways are indicated with black arrows. The ring current of the aromatic $\mathrm{I}\left[\mathrm{Cl}^{-}\right]$, III[Cl$\left.{ }^{-}\right]$and $\mathrm{III}\left[\mathrm{Cl}^{-}\right]$splits into an outer and inner pathway at each pyrrolic ring which means that all $\pi$ orbitals participate in the electron delocalization. The ring-current strengths and pathways are the about same as previously obtained at the B3LYP level. ${ }^{33}$ The strength of the ring current via the nitrogen atoms with an inner hydrogen is 
weaker than the one taking the outer route, which is common for porphyrinoids. ${ }^{48}$ The ring current along the inner pathway is slightly stronger than the outer one at the pyrrolic rings without the inner hydrogen. The ring-current strengths and pathways of the porphyrinoids without the anion are shown in the ESI. The ring current prefers the outer route at the inverted pyrrolic ring of $\mathrm{III}\left[\mathrm{Cl}^{-}\right]$, even though they have a hydrogen connected to the nitrogen.

For I $\left[\mathrm{Cl}^{-}\right]$and $\mathrm{II}\left[\mathrm{Cl}^{-}\right]$, the ring-current pathways are similar to the ones for I and II, whereas for $\mathrm{III}\left[\mathrm{Cl}^{-}\right]$almost no ring current takes the inner route at the inverted pyrrolic ring, because the $\beta$ carbons of the inverted pyrrolic rings are bent out from the porphyrinoid plane, which affects the conjugation. The ring-current strength of $\mathrm{III}\left[\mathrm{Cl}^{-}\right]$via the inner route of the pyrrolic ring with an inner hydrogen is also weak. The ring-current strengths and pathways of the $\mathrm{Cl}^{-}$complexes calculated at the B3LYP and M06-2X levels qualitatively differ, because the anions suffer from charge transfer problems at the B3LYP level that lead to stronger ring-current strengths.. The $\mathrm{Cl}^{-}$complexes of the aromatic porphyrinoids remain aromatic. However, the ring-current strengths of $\mathrm{I}\left[\mathrm{Cl}^{-}\right], \mathrm{II}\left[\mathrm{Cl}^{-}\right]$, and III $\left[\mathrm{Cl}^{-}\right]$are with $8.3 \mathrm{nA} / \mathrm{T}, 6.0 \mathrm{nA} / \mathrm{T}$, and $15.7 \mathrm{nA} / \mathrm{T}$ weaker than for I, II, and III, respectively. Thus, the anion complexes sustain ring currents that are $21-48 \%$ weaker than for the corresponding neutral forms. Thering-current strengths for the aromatic porphyrinoids (I, II, III) and their $\mathrm{Cl}^{-}$complexes are summarized in Table 1. Ring-current strengths calculated at the B3LYP level are given in the ESI.

Table 1. The integrated ring-current strengths (in nA/T) of the studied aromatic porphyrinoids and their $\mathrm{Cl}^{-}$complexes calculated at the M06-2X/def2-TZVP level of theory

\begin{tabular}{|c|c|c|}
\hline Molecule & Porphyrinoid & ${\text { The } \mathrm{Cl}^{-} \text {complex }}^{-}$ \\
\hline I & 32.8 & 24.5 \\
\hline II & 27.6 & 21.6 \\
\hline III & 32.7 & 17.0 \\
\hline
\end{tabular}

\subsubsection{Antiaromatic porphyrinoids}

Calculationson $\mathrm{IV}\left[\mathrm{Cl}^{-}\right], \mathrm{V}\left[\mathrm{Cl}^{-}\right]$and $\mathrm{VI}\left[\mathrm{Cl}^{-}\right]$show that their ring currents are paratropic flowing mainly along inner pathways as often seen for antiaromatic porphyrinoids. ${ }^{31,49}$ The ring-current 
strength along the outer pathway is much weaker. Calculations at the M06-2X/def2-TZVP level show that the $\mathrm{Cl}^{-}$complexes sustain a very weak local ring current in the pyrrolic rings, whereas the B3LYP calculations suggest that the ring current of $\mathrm{IV}\left[\mathrm{Cl}^{-}\right], \mathrm{V}\left[\mathrm{Cl}^{-}\right]$, and $\mathrm{VI}\left[\mathrm{Cl}^{-}\right]$splits at the pyrrolic rings as for the neutral form. .The ring-current strengths of the anionic complexes are $5.4 \mathrm{nA} / \mathrm{T}, 7.3 \mathrm{nA} / \mathrm{T}$, and 4.8 nAT or $25-31 \%$ weaker than for the corresponding porphyrinoid. The complexation weakens the degree of antiaromaticity, whereas it does not significantly affect the aromatic character nor the ringcurrent pathways. The ring current strengths of the antiaromatic porphyrinoids are given in Table 2 . The ring-current pathways of the anion complexes are shown in Figure 1 and in the ESI for the neutral forms. Ring-current strengths calculated at the B3LYP level are also reported in the ESI.

Table 2. Ring-current strengths (in nA/T) of the studied antiaromatic porphyrinoids and their $\mathrm{Cl}^{-}$ complexes calculated at the M06-2X/def2-TZVP level of theory.

\begin{tabular}{|c|c|c|}
\hline Molecule & Porphyrinoid & The $^{-}{ }^{-}$complex \\
\hline IV & -21.5 & -16.1 \\
\hline V & -23.5 & -16.2 \\
\hline VI & -19.0 & -14.2 \\
\hline
\end{tabular}

The ring-current strengths calculated at the M06-2X level are weaker than the ones obtained at the B3LYP level. The B3LYP functional tends to overestimate the strength of the paratropic ringcurrents of strongly antiaromatic molecules due to the incorrect shape of the long-ranged electronelectron interaction potential. ${ }^{33}$ Comparisons with ring-current strengths obtained at the second-order Møller-Plesset level suggest that about 50\% Hartree-Fock exchange is needed in the functional for obtaining accurate ring-current strengths for strongly antiaromatic molecules. ${ }^{33,50}$ The ring-current strengths calculated at the M06-2X level are therefore probably more accurate than the B3LYP ones. .

\subsubsection{VII and its $\mathrm{Cl}^{-}$and $\mathrm{SO}_{4}{ }^{2-}$ complexes}

Since neutral VII is an open-shell molecule we studied its closed-shell cation, which is an antiaromatic ring with $24 \pi$ electrons. Calculations show that it sustains a strong paratropic ring 
current of -28.4 nA/T and that its anion complexes $\mathrm{VII}\left[\mathrm{Cl}^{-}\right]$and $\mathrm{VII}\left[\mathrm{SO}_{4}{ }^{2-}\right]$ also sustain paratropic ring currents of $-20.7 \mathrm{nA} / \mathrm{T}$ and $-21.3 \mathrm{nA} / \mathrm{T}$. VII[ $\left[\mathrm{Cl}^{-}\right]$and $\mathrm{VII}\left[\mathrm{SO}_{4}{ }^{2-}\right]$ are less antiaromatic than VII, because the excess charge of the anion is partially transferred to the ring. Complexation with the anions leads a decrease in the paratropic ring-current strength of 7.1-7.7 nA/T (25-27\%).

The saturated outer pathways of the six-membered rings do not contribute much to the electron delocalization, as expected. The paratropic ring current of VII divides into a very weak outer branch of $-0.7 \mathrm{nA} / \mathrm{T}$ and $-27.7 \mathrm{nA} / \mathrm{T}$ takes the inner route. The six-membered rings of $\mathrm{VII}\left[\mathrm{Cl}^{-}\right]$and $\mathrm{VII}\left[\mathrm{SO}_{4}{ }^{2-}\right]$ sustain local diatropic ring currents of $0.6 \mathrm{nA} / \mathrm{T}$ and $1.8 \mathrm{nA} / \mathrm{T}$, respectively. The calculated ringcurrent strengths of VII and its $\mathrm{Cl}^{-}$and $\mathrm{SO}_{4}{ }^{2-}$ complexes ( $\mathrm{VII}\left[\mathrm{Cl}^{-}\right]$and $\mathrm{VII}\left[\mathrm{SO}_{4}{ }^{2-}\right]$ ) are given in Table 3. Table 3.Ring-current strengths (in nA/T) of molecule VII and its $\mathrm{Cl}^{-}$and $\mathrm{SO}_{4}{ }^{2-}$ complexes calculated at M06-2X/def2-TZVP level of theory.

\begin{tabular}{ll}
\hline Molecule & Ring-current strength \\
\hline VII & -28.4 \\
\hline VII[Cl'] & -20.7 \\
\hline $\mathrm{VII}^{-}\left[\mathrm{SO}_{4}{ }^{2-}\right]$ & -21.3 \\
\hline
\end{tabular}

\subsubsection{VIII, IX, X, and their $\mathrm{Cl}^{-}$complexes}

The molecular ring of VIII consists of five $\mathrm{C}_{4} \mathrm{~N}$ moieties of which one nitrogen has an inner hydrogen. The number of $\pi$ electrons is 26 leading to aromaticity according to the Hückel rule. The calculated ring-current strength of VIII is $5.2 \mathrm{nA} / \mathrm{T}$ indicating that it is weakly aromatic. The anionic complex of VIII is more aromatic sustaining a ring current of $14.3 \mathrm{nA} / \mathrm{T}$. Even though the outer pathway of the six-membered rings is saturated, the ring current divides into an inner and outer branch. A significant fraction of $25-50 \%$ of the ring current takes the outer route.

The molecular ring of IXwith three inner hydrogens has $28 \pi$ electrons. IX and its $\mathrm{Cl}^{-}$complex are weakly antiaromatic sustaining ring-current strengths of $-5.2 \mathrm{nA} / \mathrm{T}$ and $-4.7 \mathrm{nA} / \mathrm{T}$, respectively showing that the weak antiaromatic character of IX and IX $\left[\mathrm{Cl}^{-}\right]$is almost the same for the two molecules. The paratropic ring current flowing along the inner perimeter and the saturated sixmembered rings sustain weak diatropic ring currents of 0.2-2.1 nA/T. 
Table 4. Ring-current strengths (in nA/T) of the studied molecules VIII, IX, $\mathrm{X}$ and their $\mathrm{Cl}^{-}$complexes calculated at theM06-2X/def2-TZVP levels of theory.

\begin{tabular}{|l|c|c|}
\hline Molecule & Ring-current strength & The $\left[\mathrm{Cl}^{-}\right]$complex \\
\hline VIII & 5.2 & 14.3 \\
\hline IX & -5.2 & -4.7 \\
\hline$X$ & 1.4 & 2.4 \\
\hline
\end{tabular}

Molecules $\mathrm{X}$ and $\mathrm{X}\left[\mathrm{Cl}^{-}\right]$are weakly aromatic sustaining global diatropic ring currents of 1.4 $\mathrm{nA} / \mathrm{T}$ and $2.4 \mathrm{nA} / \mathrm{T}$, respectively. The saturated six-membered rings are locally weakly aromatic sustaining ring currents of $3.3 \mathrm{nA} / \mathrm{T}$ and $4.6 \mathrm{nA} / \mathrm{T}$ for $\mathrm{X}$ and $\mathrm{X}\left[\mathrm{Cl}^{-}\right]$, respectively. Complexation with $\mathrm{Cl}^{-}$increases the global aromaticity of VIII, whereas it has hardly any effect on the global ring-current strength of IX and X. The complexation increases the strength of the local diatropic ring current of the six-membered rings. The ring-current strength and pathways for molecules VIII, IX, $\mathrm{X}$ and their $\mathrm{Cl}^{--}$ complexes are shown in Figure 3 and summarized in Table 4.

\section{Binding energies}

The BSSE corrected binding energies for the aromatic porphyrinoid complexes are 32.3, 44.3 and $14.5 \mathrm{kcal} / \mathrm{mol}$ for $\mathrm{I}\left[\mathrm{Cl}^{-}\right], \mathrm{II}\left[\mathrm{Cl}^{-}\right]$and $\mathrm{III}\left[\mathrm{Cl}^{-}\right]$, respectively. The BSSE corrections are 5.4, 4.8, and $3.0 \mathrm{kcal} / \mathrm{mol}$. The $\mathrm{Cl}^{-}$anion is located $1.8 \AA, 2.4 \AA$ and $4.2 \AA$ above the porphyrinoid plane of $\left.\mathrm{I}^{-} \mathrm{Cl}^{-}\right]$, $\mathrm{II}\left[\mathrm{Cl}^{-}\right]$and $\mathrm{III}\left[\mathrm{Cl}^{-}\right]$, respectively. $\mathrm{I}\left[\mathrm{Cl}^{-}\right]$are $\mathrm{II}\left[\mathrm{Cl}^{-}\right]$are slightly bent with $\mathrm{Cl}^{-}$on the convex side of the molecule and the inner hydrogens are coordinated towards the anion. III[Cl$\left.{ }^{-}\right]$is also bent with the anion coordinated on the convex side. The two inverted pyrrolic rings bends out from the porphyrinoid plane with the hydrogens of the $\beta$ carbons coordinated to the anion resulting in a weakly bound anion at a large distance from the porphyrinoid ring. The charge transfer of the $\mathrm{Cl}^{-}$anion of the $\mathrm{III}\left[\mathrm{Cl}^{-}\right]$ complex is much smaller than for $\left.\mathrm{I} \mathrm{Cl}^{-}\right]$and $\mathrm{II}\left[\mathrm{Cl}^{-}\right]$. Population analyses show that $20 \%$ of the excess charge transfers from $\mathrm{Cl}^{-}$to the aromatic macrocycle of I and II and $10 \%$ for III.

The BSSE corrected binding energies of the antiaromatic porphyrinoid complexes are 33.2, 27.1 and $46.2 \mathrm{kcal} / \mathrm{mol}$ for $\mathrm{IV}\left[\mathrm{Cl}^{-}\right], \mathrm{V}\left[\mathrm{Cl}^{-}\right]$, and $\mathrm{VI}\left[\mathrm{Cl}^{-}\right]$, respectively, which are of the same size as for 
two of the aromatic ones. The BSSE correction energies are 4.7, 5.7 and $5.3 \mathrm{kcal} / \mathrm{mol}$. IV[Cl'] is slightly bent with $\mathrm{Cl}^{-}$on the convex side of the molecule and the inner hydrogens are coordinated towards the anion. $\mathrm{V}\left[\mathrm{Cl}^{-}\right]$and $\mathrm{VI}\left[\mathrm{Cl}^{-}\right]$are almost planar with the inner hydrogens bent out from the plane pointing towards the anion. The Cl-anion is located $2.4 \AA, 1.2 \AA$ and $1.8 \AA$ above the porphyrinoidplane of $\mathrm{IV}\left[\mathrm{Cl}^{-}\right], \mathrm{V}\left[\mathrm{Cl}^{-}\right]$and $\mathrm{VI}\left[\mathrm{Cl}^{-}\right]$, respectively. The charge of the $\mathrm{Cl}^{-}$anion is $-0.82 e$ for $\mathrm{IV}\left[\mathrm{Cl}^{-}\right]$and $\mathrm{V}\left[\mathrm{Cl}^{-}\right]$and $-0.79 e$ for $\mathrm{VI}\left[\mathrm{Cl}^{-}\right]$. Thus, about $20 \%$ of the negative charge is transferred to the macrocycles.

The macroring of VII is almost planar with the saturated outer moiety of the six-membered rings bent out from the plane. The main ring of $\mathrm{VII}\left[\mathrm{Cl}^{-}\right]$and $\mathrm{VII}\left[\mathrm{SO}_{4}{ }^{2-}\right]$ is slightly ruffled with the anion largely in the middle of the macroring. We did not calculate any binding energies for the $\mathrm{VII}\left[\mathrm{Cl}^{-}\right.$ ] and $\mathrm{VII}\left[\mathrm{SO}_{4}{ }^{2-}\right]$ complexes, because the binding energies are dominated by the ionic interaction energy between the positive molecular ring and the anion. Population analysis for $\mathrm{VII}\left[\mathrm{Cl}^{-}\right]$yielded a charge of the $\mathrm{Cl}^{-}$anion of -0.92 e. Thus, only $8 \%$ of its charge is transferred to the macrocycle. For $\mathrm{VII}\left[\mathrm{SO}_{4}{ }^{2-}\right]$, the calculated charge of $\mathrm{SO}_{4}{ }^{2-}$ is $-1.52 e$ implying that about $20 \%$ of the charge of the dianion is transferred to the macrocycle.

The main ring of VIII is ruffled. The saturated moieties of the six-membered rings are bent out from the plane. The anion of VIII $\left[\mathrm{Cl}^{-}\right]$in the macro ring plane is coordinated to the inner hydrogen. The macro ring is less distorted than for VIII. Three of the five six-membered rings of IX are in the same plane, whereas two of the six-membered rings with an inner hydrogen are significantly bent out from that plane. The anion of $\mathrm{IX}_{\left.\mathrm{Cl}^{-}\right]}$is coordinated to the three inner hydrogens, which leads to a more planar but still ruffled structure. $\mathrm{X}$ and $\mathrm{X}\left[\mathrm{Cl}^{-}\right]$have similar structures as IX and $\mathrm{IX}\left[\mathrm{Cl}^{-}\right]$. The anion in the middle of the macro ring of $\mathrm{X}\left[\mathrm{Cl}^{-}\right]$is coordinated to all five inner hydrogens. The BSSE corrected binding energies for $\mathrm{VIII}\left[\mathrm{Cl}^{-}\right], \mathrm{IX}\left[\mathrm{Cl}^{-}\right]$and $\mathrm{X}\left[\mathrm{Cl}^{-}\right]$are 41.1, 54.4, and $67.6 \mathrm{kcal} / \mathrm{mol}$, respectively, which is of the same size as the gas phase binding energy of $\mathrm{Cl}^{-}$with triazolophane. ${ }^{51}$ The BSSE correction energies are 4.6, 4.8 and $5.1 \mathrm{kcal} / \mathrm{mol}$. 


\subsection{Excitation energies}

The $\mathrm{S}_{0} \rightarrow \mathrm{S}_{3}$ and $\mathrm{S}_{0} \rightarrow \mathrm{S}_{4}$ Singlet transitions of I[Cl$\left.{ }^{-}\right]$and II $\left[\mathrm{Cl}^{-}\right]$involve charge transfer from the 3p orbitals of the $\mathrm{Cl}^{-}$to the LUMO of the porphyrinoid. For III[Cl$\left.{ }^{-}\right]$, the four lowest electronic singlet transitions $\left(\mathrm{S}_{0} \rightarrow \mathrm{S}_{1}, \mathrm{~S}_{0} \rightarrow \mathrm{S}_{2}, \mathrm{~S}_{0} \rightarrow \mathrm{S}_{3}\right.$ and $\mathrm{S}_{0} \rightarrow \mathrm{S}_{4}$ ) have charge transfer character. The $\mathrm{S}_{0} \rightarrow \mathrm{S}_{1}$ transition of $\left.\mathrm{I}_{\mathrm{Cl}}^{-}\right]$and $\mathrm{III}\left[\mathrm{Cl}^{-}\right]$is mainly a transition from the highest occupied molecular orbital (HOMO) to the lowest unoccupied molecular orbital (LUMO). For II[Cl-], the $\mathrm{S}_{0} \rightarrow \mathrm{S}_{2}$ transition is dominated by the HOMO-LUMO transition. The calculated excitation energies for $\mathrm{I}\left[\mathrm{Cl}^{-}\right], \mathrm{II}\left[\mathrm{Cl}^{-}\right]$and $\mathrm{III}\left[\mathrm{Cl}^{-}\right]$are listed in Table 5.

Table 5.Vertical excitation energies (in eV) and the oscillator strengths (f) of the $\left.\left.\mathrm{I}^{2} \mathrm{Cl}^{-}\right], \mathrm{II}^{\mathrm{C}} \mathrm{Cl}^{-}\right]$, and $\mathrm{III}\left[\mathrm{Cl}^{-}\right]$calculated at the M06-2X level.

\begin{tabular}{llll}
\hline Molecule & State & Energy & $\mathrm{f}$ \\
\hline \multirow{4}{*}{$\left.\mathrm{I}^{-} \mathrm{Cl}^{-}\right]$} & $\mathrm{S}_{1}$ & 2.12 & 0.02 \\
\cline { 2 - 4 } & $\mathrm{S}_{2}$ & 2.17 & 0.01 \\
\cline { 2 - 4 } & $\mathrm{S}_{3}$ & 3.14 & 0.83 \\
\cline { 2 - 4 } & $\mathrm{S}_{4}$ & 3.19 & 0.30 \\
\hline \multirow{5}{*}{$\mathrm{II}\left[\mathrm{Cl}^{-}\right]$} & $\mathrm{S}_{1}$ & 1.73 & 0.35 \\
\cline { 2 - 4 } & $\mathrm{S}_{2}$ & 1.78 & 0.52 \\
\hline & $\mathrm{S}_{3}$ & 2.77 & 0.0 \\
\hline \multirow{3}{*}{$\mathrm{III}\left[\mathrm{Cl}^{-}\right]$} & $\mathrm{S}_{4}$ & 2.95 & 0.0 \\
\cline { 2 - 4 } & $\mathrm{S}_{1}$ & 1.67 & 0.06 \\
\cline { 2 - 4 } & $\mathrm{S}_{2}$ & 1.74 & 0.04 \\
\cline { 2 - 4 } & $\mathrm{S}_{3}$ & 1.75 & 0.0 \\
\cline { 2 - 4 } & $\mathrm{S}_{4}$ & 1.77 & 0.02 \\
\hline
\end{tabular}

For antiaromatic $\left.\mathrm{IV}_{\mathrm{CCl}}^{-}\right], \mathrm{V}\left[\mathrm{Cl}^{-}\right]$and $\mathrm{VI}\left[\mathrm{Cl}^{-}\right]$, the $\mathrm{S}_{0} \rightarrow \mathrm{S}_{1}$ excitation is dominated by the HOMO-LUMO transition that is strongly magnetic dipole allowed, which is typical for strongly antiaromatic molecules. $^{32}$ This transition is also responsible for the main contribution to the paratropic ring current of antiaromatic molecules. ${ }^{32}$ Higher-lying transitions $\left(S_{0} \rightarrow S_{2}, S_{0} \rightarrow S_{3}\right.$ and $\left.S_{0} \rightarrow S_{4}\right)$ have charge transfer character from 3p orbitals of the $\mathrm{Cl}^{-}$anion to the LUMO of the porphyrinoid. The calculated excitation energies for $\mathrm{IV}\left[\mathrm{Cl}^{-}\right], \mathrm{V}\left[\mathrm{Cl}^{-}\right]$and $\mathrm{VI}\left[\mathrm{Cl}^{-}\right]$are reported in Table 6. 
Table 6.Vertical excitation energies (in eV) and the oscillator strengths (f) of the IV[Cl-], $\left.\mathrm{V}^{-} \mathrm{Cl}^{-}\right]$, and $\mathrm{VI}\left[\mathrm{Cl}^{-}\right]$calculated at the M06-2X level.

\begin{tabular}{|llll|}
\hline Molecule & State & Energy & f \\
\hline $\mathrm{IV}\left[\mathrm{Cl}^{-}\right]$ & $\mathrm{S}_{1}$ & 1.60 & 0.0 \\
\hline & $\mathrm{S}_{2}$ & 2.85 & 0.01 \\
\hline & $\mathrm{S}_{3}$ & 2.96 & 0.02 \\
\hline & $\mathrm{S}_{4}$ & 3.13 & 0.33 \\
\hline $\mathrm{V}\left[\mathrm{Cl}^{-}\right]$ & $\mathrm{S}_{1}$ & 1.55 & 0.0 \\
\hline & $\mathrm{S}_{2}$ & 2.47 & 0.0 \\
\hline & $\mathrm{S}_{3}$ & 2.48 & 0.0 \\
\hline & $\mathrm{S}_{4}$ & 2.52 & 0.0 \\
\hline $\mathrm{VI}\left[\mathrm{Cl}^{-}\right]$ & $\mathrm{S}_{1}$ & 1.63 & 0.0 \\
\hline & $\mathrm{S}_{2}$ & 2.97 & 0.75 \\
\hline & $\mathrm{S}_{3}$ & 3.27 & 0.48 \\
\hline & $\mathrm{S}_{4}$ & 3.61 & 0.25 \\
\hline
\end{tabular}

The lowest electronic transitions of $\mathrm{VII}\left[\mathrm{Cl}^{-}\right]$lead to charge transfer from the 3p orbitals of the $\mathrm{Cl}^{-}$anion to the LUMO on the porphyrinoid. For VII[SO$\left.{ }_{4}{ }^{2-}\right]$, the lowest excitations lead to charge transfer from the 2p orbitals of the oxygens of $\mathrm{SO}_{4}{ }^{2-}$ to the LUMO on the porphyrinoid. The excitation energies for $\mathrm{VII}\left[\mathrm{Cl}^{-}\right]$and $\mathrm{VII}\left[\mathrm{SO}_{4}{ }^{2-}\right]$ are given in Table 7.

Table 7.Vertical excitation energies (in eV) and the oscillator strengths (f) of $\mathrm{VII}\left[\mathrm{Cl}^{-}\right]$and $\mathrm{VII}\left[\mathrm{SO}_{4}{ }^{2-}\right]$ calculated at the M06-2X level.

\begin{tabular}{|llll|}
\hline Molecule & State & Energy & $\mathrm{f}$ \\
\hline $\left.\mathrm{VII}^{-} \mathrm{Cl}^{-}\right]$ & $\mathrm{S}_{1}$ & 0.78 & 0.04 \\
\hline & $\mathrm{S}_{2}$ & 1.18 & 0.0 \\
\hline & $\mathrm{S}_{3}$ & 1.26 & 0.0 \\
\hline & $\mathrm{S}_{4}$ & 1.29 & 0.0 \\
\hline $\mathrm{VII}\left[\mathrm{SO}_{4}{ }^{2-}\right]$ & $\mathrm{S}_{1}$ & 0.66 & 0.0 \\
\hline & $\mathrm{S}_{2}$ & 0.67 & 0.0 \\
\hline & $\mathrm{S}_{3}$ & 0.83 & 0.04 \\
\hline & $\mathrm{S}_{4}$ & 0.87 & 0.01 \\
\hline
\end{tabular}

\section{CONCLUSIONS}


Magnetically induced current densities and vertical excitation energies have been studied at the DFT and TDDFT levels for anionic complexes of sapphyrin (I), cyclo[6]carbon (II), rubyrin (III), which are aromatic expanded porphyrinoids. Similar calculations were performed on the $\mathrm{Cl}^{-}$ complexes of orangarin (IV), rosarin (V) and amethyrin (VI), which are antiaromatic expanded porphyrinoids. The effect of the anion complexation on the magnetic properties was investigated, since to the best of our knowledge such studies have not been previously reported. Analysis of the electron density showed that in the anion complex up to $20 \%$ of the excess charge is transferred from the anion to the molecular ring weakening the ring-current strength by $25-30 \%$ for the antiaromatic porphyrinoids. Anion complexation also weakens the ring-current strength of the aromatic expanded porphyrinoids by 21-48\%, whereas the complexation did generally not affect the ring-current pathways. The present study shows that anion complexation can in principle be used for modifying the aromatic and antiaromatic character of molecules. However, for the investigated compounds the effect on the ring-current strength is too small to alter their aromatic character.

Calculations of the $\mathrm{Cl}^{-}$binding energies of the aromatic and antiaromatic porphyrinoids yielded about the same energies except for $\mathrm{III}\left[\mathrm{Cl}^{-}\right]$, which binds $\mathrm{Cl}^{-}$very weakly since the cavity inside the porphyrin ring is too small to fit the anion.

A strongly antiaromatic molecule (VII) was designed by saturating the $\mathrm{CH}$ moieties of the outer perimeter of the benzene rings of pentacyanobenzo[25]annulene. Analogous heterocyclic molecules (VIII, IX and X) were constructed by replacing the inner $\mathrm{CH}$ groups of the six-membered rings with isoelectronic nitrogen moieties and adding hydrogens to adjust the number of electrons of the macrocycle. The obtained heterocycles were found to have large complexation energies with $\mathrm{Cl}^{-}$ anions. The anion in the middle of the macroring of $\mathrm{X}\left[\mathrm{Cl}^{-}\right]$is coordinated to all five inner hydrogens leading to a large binding energy of $67.6 \mathrm{kcal} / \mathrm{mol}$.

TDDFT calculations of the lowest excited states of the anionic porphyrinoid complexes show that the electronic transitions lead to charge transfer from the anion to the molecular ring except the 
$\mathrm{S}_{0} \rightarrow \mathrm{S}_{1}$ transitionof the antiaromatic porphyrinoids, which is dominated by the HOMO-LUMO transition that is responsible for the main contribution to their paratropic ring current.

\section{Electronic supplementary information (ESI)}

The Cartesian coordinates of the optimized molecular structures, excitation properties of the lowest excited states of the anion complexes, pictures of frontier orbitals, binding energies, and ring-current strengths calculated at the B3LYP/def2-TZVP level are given in the ESI.Ring-current pathways calculated at the M06-2X/def2-TZVP level for the porphyrinoids without the anion are also given in the ESI. See DOI: $\mathrm{xx} \cdot \mathrm{xxxx} / \mathrm{xxxxxxxxxx}$

\section{Acknowledgments}

R.R.V. and D.S. thank for funding from the Academy of Finland (projects 325369 and 314821).Wealso thank CSC-the Finnish IT Center for Science and the Finnish Grid and Cloud Infrastructure (persistent identifierurn:nbn:fi:research-infras-2016072533)for computational time.

R.R.V. thanks the Tomsk Polytechnic University Competitiveness Enhancement Program (VIURSCABS-142/2019) for support.

\section{REFERENCES}

1. T. M. Krygowski and M. K. Cyrański, Chem. Rev., 2001,101,1385-1419.

2. M. K. Cyrański, Chem. Rev., 2005, 105, 3773-3811.

3. H. Fliegl, R. R. Valiev, F. Pichierri and D. Sundholm, Chemical Model., 2018, 14, 1-42.

4. D. Sundholm, H. Fliegl and R. J. F Berger,Wiley Interdiscip. Rev.(WIREs),2016, 6, 639-678.

5. C. Kumar, H. Fliegl and D. Sundholm, J. Phys. Chem. A,2017, 121, 7282-7289.

6. G. Monaco and R. Zanasi,Phys. Chem. Chem. Phys., 2019,21, 11564-11568.

7. M. Dimitrova, H. Fliegl and D. Sundholm, Phys. Chem. Chem. Phys., 2017, 19, 20213-20223. 
8. R. R. Valiev, H. Fliegl and D. Sundholm, Phys. Chem. Chem. Phys.,2018, 20, 17705-17713.

9. D. Sundholm, H. Fliegl and R. J. F. Berger, Phys. Chem. Chem. Phys., 2016, 18, 15934-15942.

10. H. Omori, S. Hiroto, Y. Takeda, H. Fliegl, S. Minakata and H. Shinokubo, J. Am. Chem. Soc., 2019, 141, 4800-4805.

11. A. Nishiyama, M. Fukuda, S. Mori, K. Furukawa, H. Fliegl, H. Furuta and S. Shimizu,Angew. Chem. Int. Ed. Engl., 2018, 57, 9728-9733.

12. R. Nozawa, J. Kim, J. Oh, A. Lamping, Y. Wang, S. Shimizu, I. Hisaki, T. Kowalczyk, H. Fliegl, D. Kim and H. Shinokubo, Nat. Commun.,2019, 10, 3576.

13. R. Mitchell,Chem. Rev.,2001, 101, 1301-1315.

14. S. Slayden and J. Liebman, Chem. Rev.,2001, 101, 1541-1566.

15. W. Herndon and N. Mills,J. Org. Chem.,2005, 70, 8492-8496.

16. H. Fliegl, S. Taubert, O. Lehtonen and D. Sundholm,Phys. Chem. Chem. Phys., 2011, 13, 20500 $-20518$.

17. R. R. Valiev, H. Fliegl and D. Sundholm,Phys. Chem. Chem. Phys.,2015, 17, 14215-14222.

18. R. R. Valiev, H. Fliegl and D. Sundholm,Phys. Chem. Chem. Phys.,2014, 16, 11010-11016.

19. I. Benkyi, H. Fliegl, R. R. Valiev and D. Sundholm, Phys. Chem. Chem. Phys.,2016, 18, 1193211941.

20. R. R. Valiev, H. Fliegl and D. Sundholm,Chem. Comm., 2017, 53, 9866-9869.

21. R. R. Valiev, H. Fliegl and D. Sundholm,J. Phys. Chem. A., 2015, 119, 1201-1207.

22. R. Paolesse, S. Nardis, D. Monti, M. Stefanelli and C. Natale,Chem. Rev., 2017, 117, 25172583.

23. T. Woller, P. Geerlings, F. De Proft, B. Champagne and M. Alonso,Molecules, 2018, 23, E1333.

24. T. Stuyver, P. Geerlings, F. De Proft and M. Alonso, J. Phys. Chem. C., 2018, 122, 2443624444. 
25. G.Li, A. Dilger, P. Cheng, W. Ewing and J. Groves, Angew. Chem. Int. Ed.,2017, 57, 12511255.

26. A. Endo, M. Ogasawara, A. Takahashi, D. Yokoyama, Y. Kato and Ch. Adachi,Adv. Mater.,2009, 21, 4802-4806.

27. M. Ethirajan, Y. Chen, P. Joshi and R. Pandey,Chem. Soc. Rev., 2010, 40, 340-362.

28. H. Lee, K. Hong and W. Jang,Coord. Chem. Rev., 2018, 354, 46-73.

29. G. Cárdenas-Jirón, M. Borges-Martínez, R. Mera-Adasmeand R. Pino-Rios, Int. J. Quantum Chem., 2019, 119, e25789.

30. H. Fliegl, O. Lehtonen, D. Sundholmand V. Kaila, Phys. Chem. Chem. Phys., 2010, 13, 434437.

31. R. R. Valiev, H. Fliegl and D. Sundholm,Phys. Chem. Chem. Phys., 2017, 19, 25979-25988.

32. R. R. Valiev, G. Baryshnikov and D, Sundholm,Phys. Chem. Chem. Phys.,2018, 20, 3023930246.

33. R. R. Valiev, I. Benkyi, Yu.Konyshev, H. Fliegl and D. Sundholm,J. Phys. Chem.,2018, 122, 4756-4767.

34. H. D. Root, D. N. Mangel, J. T. Brewster, H. Zafar, A. Samia, G. Henkelman and J. L. Sessler, Chem. Commun.,2020, Advance Article.

35. Y. Zhao, N. Schiltz and D. Truhlar,J. Chem. Theory Comput., 2006, 2, 364-382.

36. F. Weigendand R. Ahlrichs, Phys. Chem. Chem. Phys., 2005, 7, 3297-3305.

37. S. Lee, Ch. Chen and A. Flood, Nature Chem., 2013, 5, 704-710.

38. S. F. Boys and F. Bernardi, Mol. Phys., 1970,19, 553-566.

39. H. B. Jansen and P. Ros, Chem. Phys. Lett., 1969, 3, 140-143.

40. M. J. Frisch, G. W. Trucks, H. B. Schlegel, G. E. Scuseria, M. A. Robb, J. R. Cheeseman, V. G. Zakrzewski, J. A. Montgomery Jr, R. E. Stratmann, J. C. Burant, S. Dapprich, J. M. Millam, A. D. Daniels, K. N. Kudin, M. C. Strain, O. Farkas, J. Tomasi, V. Barone, M. Cossi, R. Cammi, B. Mennucci, C. Pomelli, C. Adamo, S. Clifford, J. Ochterski, G. A. Petersson, P. Y. Ayala, Q. 
Cui, K. Morokuma, D. K. Malick, A. D. Rabuck, K. Raghavachari, J. B. Foresman, J. Cioslowski, J. V. Ortiz, A. G. Baboul, B. B. Stefanov, G. Liu, A. Liashenko, P. Piskorz, I. Komaromi, R. Gomperts, R. L. Martin, D. J. Fox, T. Keith, M. A. Al-Laham, C. Y. Peng, A. Nanayakkara, C. Gonzalez, M. Challacombe, P. M. W. Gill, B. Johnson, W. Chen, M. W. Wong, J. L. Andres, C. Gonzalez, M. Head-Gordon, E. S. Replogle and J. A. Pople, Gaussian 16, Revision A.02, Gaussian, Inc., Pittsburgh, PA, 2016.

41. J.Jusélius and D. Sundholm, J. Chem. Phys., 2004, 121, 3952-3963.

42. M. Rauhalahti, S. Taubert, D. Sundholm and V. Liegeois, Phys. Chem. Chem. Phys., 2017, 19, 7124-7131.

43. F. Furche, R. Ahlrichs, C.Hättig, W. Klopper, M. Sierkaand F. Weigend,Wiley Interdiscip. Rev.(WIREs), 2014, 4,91-100.

44. C. Ehrhardt and R. Ahlrichs,Theor. Chem. Acc.,1985, 68, 231-245.

45. A.D. Becke, J. Chem. Phys., 1993, 98, 5648-5652.

46. C. Lee, W. Yang and R. G. Parr, Phys. Rev. B, 1988, 37, 785-789.

47. M. E. Casida and M. Huix-Rotllant, Annu. Rev. Phys. Chem., 2012,63, 287-323.

48. H. Fliegl and D. Sundholm, J. Org. Chem., 2012, 77, 3408-3414.

49. R. R. Valiev, H. Fliegl, and D. Sundholm,J. Phys. Chem. A, 2013, 117, 9062-9068.

50. A. Dreuw and M.Head-Gordon, Chem. Rev., 2005, 105,4009-4037.

51. Y. Liu, A. Sengupta, K. Raghavachari, A. Flood, Chem,2017, 3, 411-427. 